\title{
The Formation of Initial Components of Number Concepts in Mexican Children
}

\author{
Yulia Solovieva, Luis Quintanar, Gerardo Ortíz \\ Autonomous University of Puebla, Puebla, Mexico
}

\begin{abstract}
The initial formation of number concept represents one of the essential aspects of learning mathematics at the primary school. Children commonly show strong difficulties and absence of comprehension of symbolic and abstract nature of concept of number. The objective of the present study was to show the effectiveness of original method for introduction of elements of concept of number. A pre- and post- test descriptive quantitative and qualitative design was used with an experimental group of Mexican suburban children from Grade 1 of the primary school. The original method for formation of components of concept of number was applied to children from experimental group. The duration of the application was six months in the classroom three days per week. The program included specific training of components of number concept: symbolic, logical, numeric, and spatial. The results of the final assessment indicate positive result in experimental group in comparison with absence of changes in control group. The authors conclude that the method could be useful for organizing pedagogical methodology in Mexican primary schools.
\end{abstract}

Keywords: concept of number, initial teaching, school teaching, formative experiment

\section{Introduction}

The traditional system of teaching mathematics in Mexico, as in many other countries, is facing strong difficulties, especially during introduction of essential concepts in the primary school. Strong difficulties together with low school success were reported in official reports of System of Public Education in Mexico (2010-2011). According to these statistical reports, the percentage of children who can not approve mathematics at the primary school has increased during the last five years. There is no real solution of this serious problem but new proposals of methods of teaching at the primary school. In reality, such proposals are related only to administrative, political, and economic aspects of education but never to concrete ways and strategies of teaching and learning.

Historical and cultural psychology through activity theory has created appropriate background for elaboration and application of complex methods for initial acquisition of number concepts (Galperin, 1992a, 1992b; Leontiev, 2005; Talízina, 2000, 2001, 2009). Such background presumes detailed consideration of elements of structure of number concepts from psychological point of view and possibility of its gradual step-by-step formation in young children. This approach is contrasted with traditional empiric constant execution of thousands of elementary operations in school without any kind of conceptual acquisition of

Yulia Solovieva, Ph.D., Faculty of Psychology, Autonomous University of Puebla. Luis Quintanar, Ph.D., Faculty of Psychology, Autonomous University of Puebla. Gerardo Ortíz, M.C., Faculty of Psychology, Autonomous University of Puebla. 
number concepts (Resnick, 1992). From this point of view, the process of introduction of number concepts should be based on gradual formation of its elements by steps instead of traditional training of separated habits of pupils. With such habits the authors can mention arithmetic operations of addition and rest without any comprehension of the components of these operations.

Obviously, the success of acquisition of number concepts depends on the possibility of determination of structural components of these concepts (Piaget \& Szeminska, 1996). In previous publications, such components were identified and characterized (Casey, Pezaris, \& Nuttall, 1992; Salmina \& Filimonova, 2010; Solovieva, Ortiz, \& Quintanar, 2010) as shown in the following:

(1) Possibility of reflective election and usage of symbolic means in different kinds of actions;

(2) Comprehension of elementary logic operations;

(3) Knowledge of digits and of ordinal and cardinal order;

(4) Spatial orientation on material, perceptual, and verbal levels.

The objective of this study was to show the possibilities of elaboration and application of gradual introduction of the components of concept of number in a group of Mexican Grade 1 children. The method was created on the basis of the theory of historic and cultural development and activity theory.

\section{Method}

\section{Sample}

In this presentation, the authors report the initial formation of concept of number in two groups of bilingual Mexican children (Nahuatl-Spanish) who were elementary pupils of Grade 1. A pre- and post- test design was used, involving a control group $(n=22)$ and an experimental group $(n=24)$. The children never assisted pre-school education before entering primary school. All children were regular pupils of suburban area in the state of Tlaxcala that is close to the city of Puebla. The children had no disturbances of health or intellectual development. The educational level of children's parents was very low and varied from uncompleted primary school to completed primary school. In occasions, the parents were illiterate. The dominant language at home is Nahuatl. The dominant cultural language outdoors is Spanish. The teachers of the school were trying to use both languages at primary school which is rather complicated to achieve in reality.

\section{Instruments}

The assessment was accomplished with the help of the test "Level of Preparation for School” (Quintanar \& Solovieva, 2010) and special tasks for acquisition of number concepts (Solovieva, Ortiz, \& Quintanar, 2010) (see Table 1).

\section{Procedure}

All children were submitted to assessment before and after working with the programme. The assessment included different kinds of tasks directed to evaluation of the level of acquisition of the components of number concepts. One of the individual sessions was required for assessment. The same assessment was applied after application of the method in both experimental and control groups. The results were submitted to qualitative and quantitative analyses. The results of the pre- and post- test were statistically analyzed by means of a Kruskall-Wallis test. In addition, a qualitative analysis of the committed errors was performed according to the type of difficulties. 
The original method for formation of components of number concepts was applied to children from experimental group. The duration of the application was six months (from October to March) in the classroom three days per week. The school teachers assisted sessions in Spanish language provided by post-graduate students of Master Programme in Neuropsychological Diagnostic and Rehabilitation. After that, the school teachers performed the similar sessions in Nahuatl.

Table 1

Tasks for Assessment of Acquisition of Number Concepts

\begin{tabular}{ll}
\hline Level of task & Task \\
\hline \multirow{3}{*}{ Graphic level } & Copy of the house \\
& Seriation of geometric figures \\
& Identification of essential features of perceptual objects \\
& Drawing of eight animals \\
& Solution of tasks with instructions with spatial categories in perceptual level \\
\hline Concrete level & Conservation of liquids \\
& Solution of tasks with instructions with spatial categories in perceptual level \\
& Comparison of conjunctions \\
\hline & Complete the sentence with superlative word “more” \\
& Complete the sentence with superlative word "less” \\
& Complete the sentence with comparative word "major" \\
& Complete the sentence with comparative word "minor" \\
Question about relative valor of number & Oral counting in direct order \\
& Oral counting in indirect order \\
& Comprehension and elaboration of sentences with logic spatial constructions \\
\hline
\end{tabular}

The control group worked according to official program distributed by the Secretariat of Public Education in Mexico. This program does not consider the components of number concepts. The program includes knowledge of digits and constant solution to elemental mathematic operations from one to 10 and from 10 to 100 during Grade 1.

\section{The Method of Formation of Components of Number Concepts}

The program was created according to the consideration of psychological structure of the action (Leontiev, 1983) and of the concept of the zone of proximate development (Vigotsky, 1996). The objective of the experimental program was the introduction and consolidation of number concepts with the help of specific actions selected for each of the components: logic, numeric, symbolic, and spatial orientation. All actions were fulfilled on different gradual levels: material, materialized, perceptual, and verbal. For all actions, orientation based on action was elaborated and presented by one of the mentioned levels. That means that all actions were fulfilled by the guidance of an adult. All actions were distributed among all children. All children were able to take part in activities, ask questions, repeat the actions, help each other, and propose their own objects and variants of solutions.

All the tasks of the program were carried out according to proposals of step-by-step formation and structure of activity:

(1) Elaboration and usage of orientation based on actions: all actions were introduced, explained, and carried out together with an adult in the group; 
(2) Initial formation starting from external material form using concrete objects;

(3) Posterior passing of the same action into materialized (symbolic) level by application of external means and scheme;

(4) Passing of the same action into perceptual level by drawing the situation, action, or object;

(5) Generalization of the actions by usage of similar and different contents in all levels;

(6) Constant usage of verbal regulation: oral language of children and an adult.

\section{The Descriptions of the Program}

The descriptions of the program are as following:

(1) Differentiation of relevant and irrelevant characteristics in concrete objects: Tasks for identification of one's own corporal scheme and other children's corporal scheme; After that, the identification of corporal scheme was applied on perceptual level; Usage of description for identification and differentiation of the objects; Toys and concrete objects, images, and photos were used on this stage.

(2) Differentiation of relevant and irrelevant characteristics in pictures, illustrations, and representations (perceptual and symbolic level): Different symbols were used for the determination of the similar and different situations (more or less, major or minor, same or different, equal or unequal).

(3) Material and materialized representation of objects and their spatial relations: Spatial tasks for spatial orientation in concrete situations were used; Comparisons of different kinds of spatial relations were realized with different objects, concrete materials, and toys; Classification of objects according to their spatial characteristics (left or right, low or high, up or down, here or there, close or farther, in front of, between, in the center of, close to, in the middle of, and so on).

(4) Spatial orientation on the perceptive level: Tasks for spatial organization and orientation by construction of objects with the help of models; Work with spatial characteristics in illustrations and representations; Drawing of different situations with spatial orientation.

(5) Spatial orientation on the verbal level: Constructive guided tasks, verbal instructions, and games including phrases with temporal, spatial, and casual prepositions; Elaboration of phrases and sentences with spatial structures and relations: comparison, relativity, passivity, and genitive relations; Creation and usage of sentences were with relations of subordination, different prepositions, connections, cause, and effect relations.

(6) Introduction of system of logic and numeric actions: Work with one-by-one correspondence in material level, organization, and comparison of conjunctions; Construction of numeric series with the help of external orientation; Determination of each previous and each following digit in numeric series; Determination of bigger and less digits on the numeric series.

(7) The same actions of materialized (usage of means and symbols) and perceptual level (drawing of numeric series on the board and on the paper).

(8) Introduction of actions of measuring with usage of diverse options of external means (measure): Varied measuring tasks with the help of different marking means: (a) measuring longitude of diverse objects, (b) measuring the same object by little and big measures with the help of marks; (c) measuring different objects with the same marks, and (d) measuring liquids by different means: big measures and little measures; Elaboration and conscious reflection of proportion between the measure and size of the mean chosen for the measure; Number as the results of the action of measure: quantity of measuring by the usage of the same mean of marking; Two types of relations: (a) the bigger the mean of measure is, the less the number is obtained as the quantity of marking, 
and (b) the less the mean of measure is, the bigger the number is obtained as the quantity of marking.

(9) Introduction of the concept of quantity: Quantity as number of marking by using the same measuring means; Conservation of quantity (number) if the same mean for measuring is chosen; Changing of the quantity of parking if different means for parking during the measuring are used; Tasks with liquids, area, volume, and longitude on the concrete level; Constant usage of symbolization (means) for marking during the measuring; Equitation and comparison of quantities; Comprehension of the necessity of usage of the same measuring mean if it needs to compare quantities; Impossibility of comparison of quantities obtained by usage of unequal means.

(10) Changing of means for measuring: Usage of the measure which is 10 times bigger than the previous measure; Usage of the measure which is 10 times less than the previous measure.

(11) Representation of quantities by using numeric series: Tasks for identification and usage of concrete series of numeric representation; Numeric series on perceptual and verbal level; Tasks with direct and inverse order in numeric series; Series with even and odd numbers.

(12) Tasks for representation of quantities by usage of positional principle: Representation of grades of numbers; Comprehension of changing of positional value of a digit; Each next position (grade) is 10 times bigger than the previous; Each previous position (grade) is 10 times less than the following; Materialized constructions of the table with grades of numbers; Symbolic representation of each grade with its numeric content.

(13) Solution of problems as real examples of studies situations: Problems on material, perceptual, and verbal levels; Numeric representations of solutions with constant verbal comments and common discussions.

\section{Results}

The results obtained as the consequence of the usage of the method showed the advantage of the children from experimental tasks after post-test assessment. No differences between groups were detected before starting the program. Additionally, a qualitative analysis of the errors was performed. This analysis considered specific aspects of material, graphic, and verbal tasks, according to the types of errors in each task (see Table 2).

Table 2

Analysis of Errors for Graphic Tasks in Experimental and Control Group Before and After Application of Experimental Program

\begin{tabular}{|c|c|c|c|c|c|c|c|}
\hline \multirow{2}{*}{ Task } & \multirow{2}{*}{ Type of errors } & \multicolumn{2}{|c|}{ Pre-test } & \multicolumn{2}{|c|}{ Post-test } & \multicolumn{2}{|c|}{ Difference (\%) } \\
\hline & & EG & CG & EG & CG & EG & CG \\
\hline \multirow{8}{*}{ Copy of the house } & Absence of global image & 62.49 & 59.09 & 12.49 & 36.36 & -50.00 & -22.73 \\
\hline & $\begin{array}{l}\text { Changes in position of } \\
\text { elements }\end{array}$ & 66.66 & 54.54 & 16.66 & 45.45 & -50.00 & -9.09 \\
\hline & Omissions & 41.66 & 40.90 & 16.66 & 31.81 & -25.00 & -9.09 \\
\hline & Inversions & 29.16 & 31.81 & 8.33 & 18.18 & -20.83 & -13.63 \\
\hline & Substitutions & 58.33 & 54.54 & 20.83 & 40.90 & -37.50 & -13.64 \\
\hline & Incomplete lines & 74.99 & 72.72 & 41.66 & 59.09 & -33.33 & -13.63 \\
\hline & Abundant lines & 58.33 & 59.09 & 24.99 & 36.36 & -33.34 & -22.72 \\
\hline & Constant correction & 24.99 & 27.27 & 4.16 & 18.18 & -20.83 & -9.09 \\
\hline
\end{tabular}




\begin{tabular}{|c|c|c|c|c|c|c|c|}
\hline & Impossibility & 87.49 & 86.36 & 4.16 & 40.90 & -83.33 & -45.46 \\
\hline \multirow[t]{3}{*}{ Seriation } & Simplification & 24.99 & 27.27 & 0.00 & 18.18 & -24.99 & -9.09 \\
\hline & Substitution & 12.49 & 9.09 & 0.00 & 0.00 & -12.49 & -9.09 \\
\hline & Impossibility & 12.49 & 9.09 & 0.00 & 0.00 & -12.49 & -9.09 \\
\hline \multirow{2}{*}{$\begin{array}{l}\text { Identification of } \\
\text { characteristics }\end{array}$} & Irrelevant features & 95.83 & 90.90 & 37.49 & 63.63 & -58.34 & -27.27 \\
\hline & $\begin{array}{l}\text { Repetition of the same } \\
\text { feature }\end{array}$ & 12.49 & 13.63 & 4.16 & 9.09 & -8.33 & -4.54 \\
\hline \multirow{2}{*}{$\begin{array}{l}\text { Drawing of } \\
\text { animals }\end{array}$} & Irrelevant features & 100.00 & 95.45 & 12.49 & 68.18 & -87.49 & -27.27 \\
\hline & Impossibility & 45.83 & 40.90 & 8.33 & 13.63 & -37.50 & -27.27 \\
\hline \multirow{4}{*}{$\begin{array}{l}\text { Spatial relations on } \\
\text { perceptual level }\end{array}$} & Opposite preposition & 66.66 & 63.63 & 12.49 & 45.45 & -54.16 & -18.18 \\
\hline & Incorrect preposition & 83.33 & 77.27 & 16.66 & 22.72 & -66.67 & -54.54 \\
\hline & Uncompleted answer & 95.83 & 90.90 & 16.66 & 63.63 & -79.16 & -27.27 \\
\hline & Impossibility (No answer) & 20.83 & 22.72 & 4.16 & 9.09 & -16.66 & -13.63 \\
\hline
\end{tabular}

Notes. EG = experimental group; CG = control group.

The percentages of the types of errors before and after children's participation in the program are shown in Table 2. Statistic analysis pointed out that the results of tasks fulfillment were significantly higher in experimental group, considering $p=<0.05$ in Kruskal-Wallis test, after application of the program (see Table 3). All results are favorable for children from experimental group in post-test assessment.

Table 3

Statistic Difference Between Groups

\begin{tabular}{lll}
\hline Task and aspect of assessment & Pre-test & Post-test \\
\hline Copy of the house: global image & 0.217 & 0.023 \\
Copy of the house: analyses of details & 0.062 & 0.019 \\
Seriation & 0.794 & 0.035 \\
Identification of features in objects & 0.203 & 0.008 \\
Usage of details in drawing task & 0.528 & 0.041 \\
Instructions with spatial prepositions on graphic level & 0.256 & 0.032 \\
\hline
\end{tabular}

The figures (see Figures 1 and 2) show the realization of the tasks of assessment before and after application of the program in experimental and control groups. It is possible to notice that the significant differences in executions of the children are always favorable for experimental group. As the figures show, no qualitative differences in execution of assessment tasks are notable in control group in post assessment.

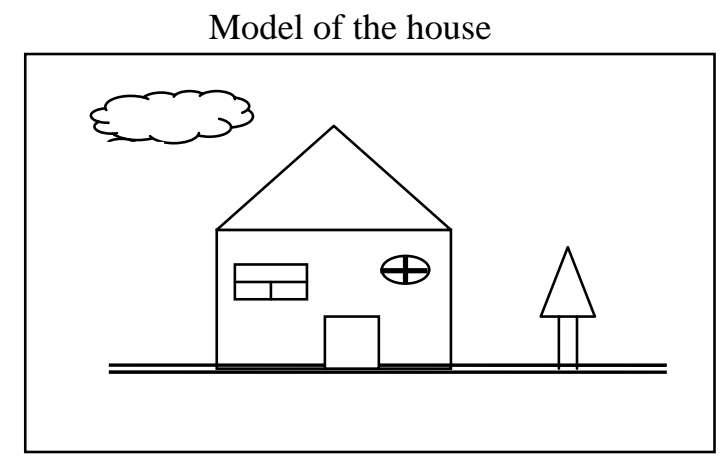




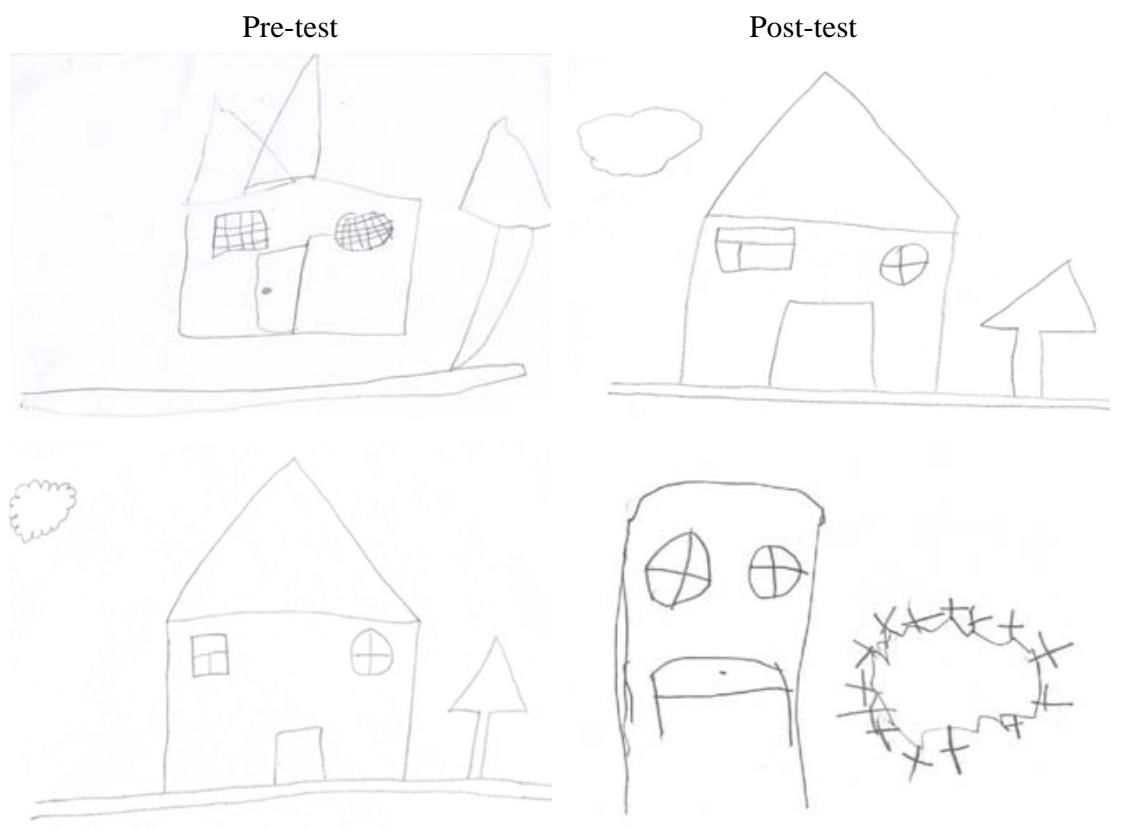

(a) Executions of experimental group

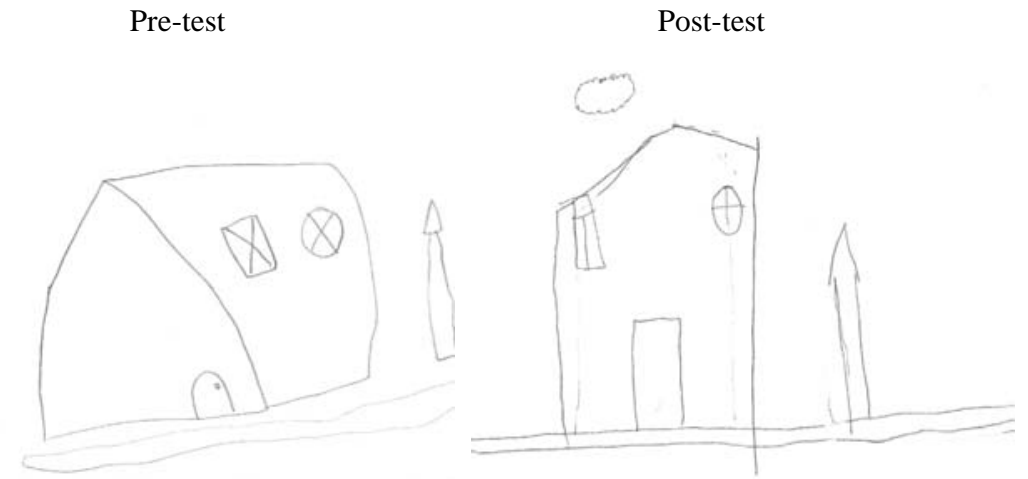

(b) Executions of control group

Figure 1. Executions of the model of the house.

Model of seriation

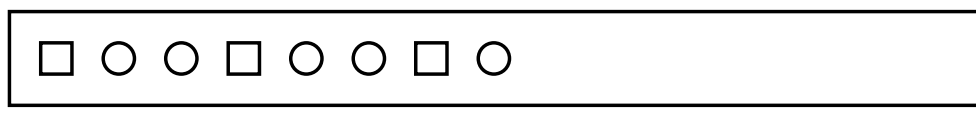

Pre-test

Post-test

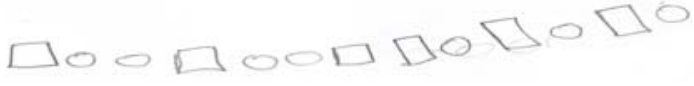

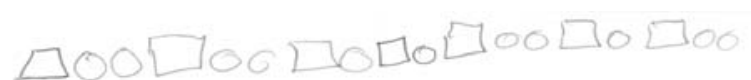

(a) Executions of control group (seriation)
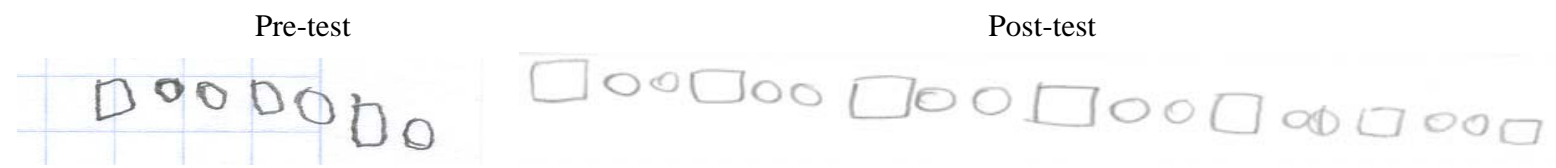

(b) Executions of experimental group (seriation)

Figure 2. Executions of the model of seriation. 
Table 4 shows the results obtained during complementary assessment of the value of digit in complex number. The children were asked about the significance (positional value) of the digits in the structure of number which consisted of two digits. The special task was chosen for this assessment. The children were asked "What the digit 1 means in number 12?" (see Table 4). Such kind of assessment permits to charge about the level of acquisition and generalization of number concepts by the children in both groups. According to Table 4, none of the children from both groups was able to explain properly the meaning of the digit (some of the children answered according to direct order and some of them according to the shape of the digit). No one could mention the positional principal of the meaning of the digit 1 in number 12 . The assessment after the implementation of the program has shown some differences between groups. It can be seen that the children from the control group were not able to answer the question correctly, as it happened in the first assessment. In the case of experimental group, it can be seen that only 24.99\% (impossibility) of the children had made mistakes while the test of them was able to answer the question.

Table 4

Results Obtained in the Tasks for Assessment of the Relative Value of the Digit of the Number on the Verbal Level: The Children Were Asked What the Digit 1 Means in Number 12

\begin{tabular}{|c|c|c|c|c|c|c|c|}
\hline & & \multicolumn{2}{|c|}{ Pre-test } & \multicolumn{2}{|c|}{ Post-test } & \multicolumn{2}{|c|}{ Difference (\%) } \\
\hline & & EG & CG & EG & CG & $\overline{E G}$ & CG \\
\hline \multirow{3}{*}{$\begin{array}{l}\text { Relative value of the } \\
\text { digit of the number }\end{array}$} & Explanation according to direct order & 29.16 & 31.81 & 24.99 & 40.90 & -4.17 & +9.09 \\
\hline & Explanation according to graphic form & 70.84 & 68.19 & 0.00 & 59.10 & -70.84 & -9.09 \\
\hline & Impossibility & 100.00 & 100.00 & 24.99 & 100.00 & -75.01 & -0.00 \\
\hline
\end{tabular}

\section{Discussion}

The basic activity of school age is the directed school learning, which involves two participants: teachers and pupils. The authors consider that only such activity guides guarantees to establish the initial numeric concepts. An important achievement of primary school is the capacity of theoretical thinking instead of empirical thinking predominant in pre-school age (Obukhova, 2006; Davidov, 2000; Solovieva \& Quintanar, 2010). According to the results of this study, it is possible to stress the importance of election of pedagogical methods for teaching mathematics at an initial level in primary school. The methods used in primary schools should have theoretical and methodological support and argumentation. The program can be used as an example of such argumentation together with some others recent publications (Pilayeva \& Akhutina, 2009). The experimental program was created according to theoretical and methodological proposals of cultural-historic psychology and activity theory. Such proposals could be very useful and productive as a method of teaching at primary schools. The authors would like to especially stress that the studied population of children had no previous preparation for introduction of elementary mathematics, even their difficult socio-demographic condition was not an obstacle on the way to gradual formation and consolidation of the components of number concepts (Solovieva \& Quintanar, 2006). The interesting fact is the majority of children from experimental group were able to charge about positional meaning of the digit in the number (digit 1 in number 12 as an example). The results confirm the essential principle of activity theory: External activity is the background for the internal activity. The source of development is not contextual surrounding of the child but type and quality of cultural activity proposed and guided by an adult. 


\section{Conclusions}

(1) The children of the studied population did not count with school readiness;

(2) The experimental program resulted to be effective according to the significant statistic differences in experimental group before and after the application of the program;

(3) It is useful to include in the program for initial mathematics' essential components of the concept of number: logic, symbolic, numeric, and spatial orientation;

(4) Traditional program of teaching does not guarantee formation of numeric concepts;

(5) Pedagogical methods based on the principles of activity theory are powerful instrument for solution to poor school success in elementary mathematics;

(6) The method used as a special activity of children at school is more significant a factor in comparison to common consideration and citation of life context and economic conditions for cultural development of children.

\section{References}

Casey, M. Pezaris, E., \& Nuttall, R. (1992). Spatial ability as a predictor of math achievement: The importance of sex and handedness patterns. Neuropsychologia, 30(I), 35-45.

Davidov, V. V. (2000). Tipos de generalización en la enseñanza. Moscú: Sociedad Pedagógica de Rusia.

Galperin, P. (1992a). Stage-by-stage formation as a method of psychological investigation. Journal of Russian and East European Psychology, 30(4), 60-80.

Galperin, P. (1992b). The problem of activity in soviet psychology. Journal of Russian and East European Psychology, 30(4), 37-59.

Leontiev, A. N. (1983). Obras psicológicas escogidas. Moscú: Universidad Estatal de Moscú.

Leontiev, A. N. (2005). On the development of arithmetical thinking in the child. Journal of Russian and East European Psychology, 43(3), 78-95.

Obukhova, L. F. (2006). Psicología del desarrollo. Moscú: Educación superior.

Piaget, J., \& Szeminska, A. (1996). Génesis del número en el niño. Argentina: Editorial Guadalupe.

Pilayeva, N. M., \& Akhutina, T. V. (2009). Escuela de multiplicación. Moscú: Terevinf.

Quintanar, L., \& Solovieva, Y. (2010). Evaluación neuropsicológica de la actividad preescolar. México: Universidad Autónoma de Puebla.

Resnick, L. (1989). Developing mathematical knowledge. American Psychologist, 44(2), 162-169.

Resnick, L. (1992). From proto-quantities to operators: Building mathematical competence on a foundation of everyday knowledge. In G. Leinhardt, R. Putnam, \& R. A. Hattrup (Eds.), Analysis of arithmetic for mathematic teaching (pp. 373-429). Hillsdale, N. J.: LEA.

Salmina, N., \& Filimonova, O. (2010). Problemas en el aprendizaje de las matemáticas básicas y su corrección. México: Instituto Universitario de Estudios Avanzados. Centro Regional para el Desarrollo de las Habilidades Cognitivas.

Solovieva, Y., \& Quintanar, L. (2006). La zona del desarrollo próximo en niños de diferentes niveles socio-culturales. Cuadernos Hispanoamericanos de Psicología, 6(2), 115-128.

Solovieva, Y., \& Quintanar, L. (2010). Antología del desarrollo psicológico del niño en la edad preescolar. Trillas, México.

Solovieva, Y., Ortiz, G., \& Quintanar, L. (2010). Formación de conceptos numéricos iniciales en una población de niños mexicanos. Cultura y educación, 3(22), 345-361.

Talízina, N. F. (2000). Manual de psicología pedagógica. México: Universidad Autónoma de San Luis Potosí.

Talízina, N. F. (2001). La formación de los conceptos matemáticos. In N. F. Talízina (Ed.), La formación de las habilidades del pensamiento matemático (pp. 21-39). México: Editorial Universitaria Potosina.

Talizina, N. F. (2009). Teoría de la actividad aplicada a la enseñanza. México: Universidad autónoma de Puebla.

Vygotsky, L. S. (1996). Obras escogidas. Tomo IV, España: Aprendizaje Visor. 